\title{
High Temperature FeB-type Phases in the Systems $\mathrm{Ta}-\{\mathrm{Ti}, \mathrm{Zr}, \mathrm{Hf}\}-\mathrm{B}$
}

\author{
F. Failamani, K. Göschl, G. Reisinger, C.A. Nunes, G. C. Coelho, A.J.S. Machado, L.E. Correa, \\ J.C.P. dosSantos, G. Giester, and P. Rogl
}

\author{
(Submitted July 12, 2015; in revised form September 19, 2015; published online October 26, 2015)
}

\begin{abstract}
Novel FeB-type phases have been evaluated in the systems $\mathrm{Ta}-\{\mathrm{Ti}, \mathrm{Zr}, \mathrm{Hf}\}-\mathrm{B}$ either from as cast or arc treated samples by $x$-ray powder and single crystal diffraction as well as electron probe microanalysis. In each of the three systems the formation of the FeB-type phase suggests a high temperature stabilization of a binary group IV metal monoboride with FeB-type. This holds true for Ti and $\mathrm{Hf}$, while for $\mathrm{Zr}$ the single crystal study of $(\mathrm{Ta}, \mathrm{Zr}) \mathrm{B}$ proves that it is a true ternary phase, as no stable monoboride exists in the binary $\mathrm{Zr}$-B system. EPMA analyses reveal that the FeB-type phases $\mathrm{Ta}\{\mathrm{Ti}, \mathrm{Zr}, \mathrm{Hf}\} \mathrm{B}$ are formed by substitution of $\mathrm{Ta}$ in $\mathrm{TaB}$ by rather small amounts of group IV elements ( $\sim 3$ at.\% of $\mathrm{Zr}, \sim 7$ at.\% $\mathrm{Hf}$, and $\sim 10$ at.\% Ti).
\end{abstract}

Keywords crystal structure, microstructure, refractory materials, $\mathrm{x}$-ray analysis

\section{Introduction}

Monoborides of transition metals ( $\mathrm{T}$ ) constitute a unique group of crystal structures with characteristic infinite boron zig-zag chains compatible with covalent single bonds at a distance of $0.165 \mathrm{~nm}<\mathrm{d}_{\mathrm{B}-\mathrm{B}}<0.190 \mathrm{~nm}$ and a bond angle of $\sim 115^{\circ}{ }^{[1]}$ As the boron atoms are coordinated by trigonal metal prisms, which share two of their rectangular faces, the crystal structures consist of infinite rows of metal prisms. The structure types of $\mathrm{FeB}, \mathrm{CrB}$ (also described as T $\ell \mathrm{I}$-type) and $\alpha \mathrm{MoB}$ are the most widely found binary monoborides. ${ }^{[1,2]} \mathrm{As}$ shown in Fig. 1, simple geometrical relationships exist, which shift blocks of FeB- into CrB-type ${ }^{[3]}$ or blocks of $\mathrm{CrB}$ type into $\alpha \mathrm{MoB}$-type ${ }^{[4]}$ Due to these geometrically defined shift operations, randomly appearing shifts reduce the intensities of certain $\mathrm{x}$-ray powder reflections in for instance a powder spectrum recorded on fine FeB powders synthe-

F. Failamani, K. Göschl, G. Reisinger, and P. Rogl, Institute of Materials Chemistry and Research, University of Vienna, Währingerstrasse 42, A-1090 Wien, Austria; C.A. Nunes, A.J.S. Machado, L.E. Correa, and J.C.P. dos Santos, Universidade de São Paulo (USP), Escola de Engenharia de Lorena (EEL), Polo UrboIndustrial Gleba AI-6, Caixa Postal 116 Lorena, SP 12602-810, Brazil; G.C. Coelho,Universidade de São Paulo (USP), Escola de Engenharia de Lorena (EEL), Polo Urbo-Industrial Gleba AI-6, Caixa Postal 116 Lorena, SP 12602-810, Brazil and Mestrado Profissional em Materiais, Centro Universitário de Volta Redonda, Av. Paulo Erlei Alves Abrantes 1325, Volta Redonda, RJ 27240-560, Brazil; and G. Giester, Institute of Mineralogy and Crystallography, University of Vienna, Althanstrasse 14, A-1090 Vienna, Austria. Contact e-mails: peter.franz.rogl@univie.ac.at. and fai.failamani@gmail.com. sized at $650{ }^{\circ} \mathrm{C}$ (for details see Ref 5). A random stacking of $\mathrm{CrB}$ - and FeB-type units may freeze as an orthorhombic low temperature modification of $\mathrm{FeB}\left(<650{ }^{\circ} \mathrm{C}\right) .{ }^{[6]}$ From nearneighbor diagrams it became obvious that the monoborides follow strong metal-boron interactions. ${ }^{[7]}$

Simple shifts of structure slabs usually do not involve large transformation energies - thus most binary metal monoborides exhibit low and high temperature modifications for which a graphical distribution is shown in Fig. 2. Whereas the FeB-type involves the electropositive metals $\mathrm{Ti}$, Hf as well as the 3d-metals $\mathrm{Mn}, \mathrm{Fe}, \mathrm{Co}$, we see a gradual decrease in stability towards $\mathrm{CrB}$ and $\mathrm{MoB}$ variants moving towards the more electronegative metals. It is interesting to note that the monoborides of the $\mathrm{Cr}, \mathrm{Mo}, \mathrm{W}$ group exhibit a CrB-type high temperature modification and a low-temperature aMoB-type, but we so far only know the CrB-type for the neighbouring $\mathrm{V}, \mathrm{Nb}, \mathrm{Ta}$ group. The group of platinum metals sees a set of structures which are prone to defect sublattices such as $\{\mathrm{Ru}, \mathrm{Os}, \mathrm{Ir}\} \mathrm{B}$ (WC-type $=\mathrm{AlB}_{2}$-type with ordered $\mathrm{B}$-defect), $\mathrm{RhB}$ and $\mathrm{PtB}_{1-\mathrm{x}}$ (NiAs-type derivatives) etc. (for details see Ref 1,2 and references therein).

Adding to binary transition metal borides a second transition metal component to form a ternary monoboride $\mathrm{TI}_{1-\mathrm{x}} \mathrm{TII}_{\mathrm{x}} \mathrm{B}$ (TI and TII are transition metals) usually leads to extended solid solutions eventually stabilizing one of the other monoboride structures or a novel arrangement such as the $\mathrm{NbCoB}_{2}$-type, which is an ordered combination of $\mathrm{FeB}$ and CrB-type units. ${ }^{[1]}$ From the unsymmetrical distribution of the binary monoboride structure types among the transition metals, it appeared of interest to investigate the most refractory metal-boron combinations such as $\{\mathrm{Ti}, \mathrm{Zr}, \mathrm{Hf}\}-\mathrm{Ta}-\mathrm{B}$. The corresponding phase equilibria have hitherto been determined at moderate temperatures (see Fig. 3) and, for the sections TaB- $\{\mathrm{Ti}, \mathrm{Zr}, \mathrm{Hf}\} \mathrm{B}$, have revealed extended solution phases of Ti, $\mathrm{Zr}, \mathrm{Hf}$ in $\mathrm{TaB}$ and $\mathrm{Ta}$ in TiB. ${ }^{[8-10]}$ It should be noted here that HfB (FeB-type) was not considered for the equilibria at $1400{ }^{\circ} \mathrm{C},{ }^{[10]}$ although earlier studies have documented its existence and peritectic decomposition at $2218{ }^{\circ} \mathrm{C} \cdot .^{[11-13]} \mathrm{ZrB}$ with NaCl-type is 

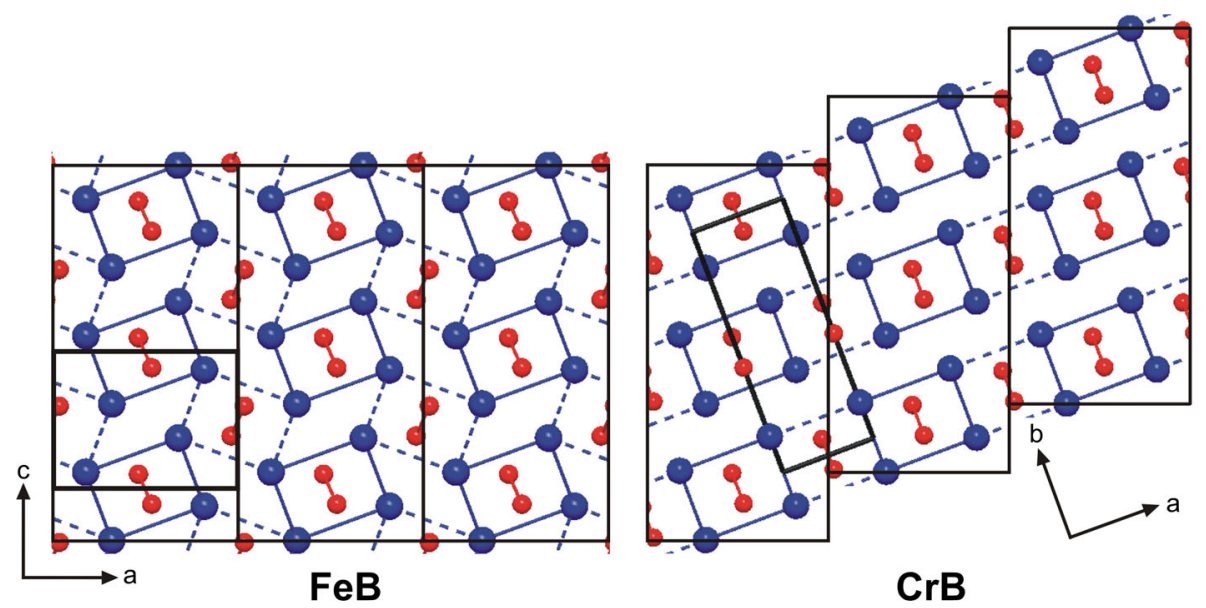

$$
\begin{aligned}
& \mathrm{V}_{\mathrm{FeB}}=\mathrm{V}_{\mathrm{CrB}} \Leftrightarrow \mathrm{a}_{\mathrm{FeB}} \times b_{\mathrm{FeB}} \times \mathrm{c}_{\mathrm{FeB}}=\mathrm{a}_{\mathrm{CrB}} \times \mathrm{b}_{\mathrm{CrB}} \times \mathrm{c}_{\mathrm{CrB}} \\
& \mathrm{a}_{\mathrm{FeB}}=\frac{2 \times \mathrm{a}_{\mathrm{CrB}} \times \mathrm{b}_{\mathrm{CrB}}}{\sqrt{\mathrm{a}_{\mathrm{CrB}}^{2}+\mathrm{b}_{\mathrm{CrB}}^{2}}} ; b_{\mathrm{FeB}}=c_{\mathrm{CrB}} ; \mathrm{c}_{\mathrm{FeB}}=\frac{1}{2} \sqrt{\mathrm{a}_{\mathrm{CrB}}^{2}+\mathrm{b}_{\mathrm{CrB}}^{2}} \\
& \text { (a) }
\end{aligned}
$$

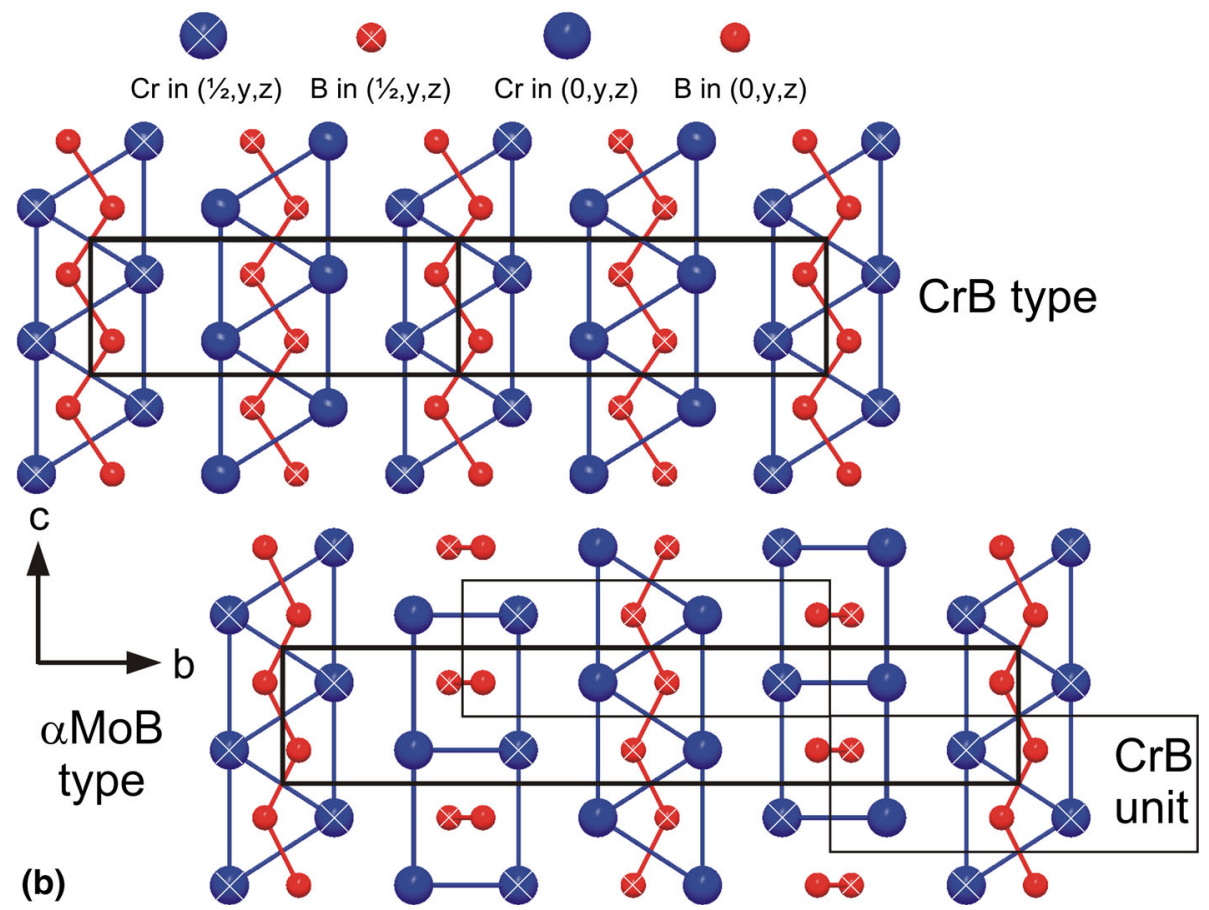

Fig. 1 (a) Upper panel, left: projection of the FeB structure along its b-axis; upper panel, right: shift of three slabs of the FeB-type atom arrangement along $1 / 2 \mathrm{c}$ creating the atom arrangement of the CrB-type. Metal atoms in blue; boron atoms in red. The unit cells of $\mathrm{FeB}$ and $\mathrm{CrB}$ (both orthorhombic) are outlined with bold frames. (b) Lower panel, top: the structures of $\mathrm{CrB}$ and of $\alpha \mathrm{MoB}$, both projected along the a-axis; lower panel, bottom: schematic arrangement of CrB-type slabs; every second CrB slab is shifted by $1 / 2$ a $+1 / 2 \mathrm{c}$ and creates the atom arrangement of $\alpha \mathrm{MoB}$. Random stacking faults may appear creating diffuse $\mathrm{x}$-ray reflections (Color figure online)

impurity $(\mathrm{C}, \mathrm{N}, \mathrm{O})$ stabilized, but the degree of thermodynamic stability of the ZrB-phase with FeB-type has been evaluated. ${ }^{[14]}$ With an estimated heat of formation of $\Delta \mathrm{H}_{\mathrm{f}}^{0} \sim-84 \mathrm{~kJ} /(\mathrm{g}$. at.ZrB $)$ it was shown that $\mathrm{ZrB}$ with $\mathrm{FeB}-$ type can only be stable below $590{ }^{\circ} \mathrm{C}$ with respect to $\alpha \mathrm{Zr}$ and $\mathrm{ZrB}_{2}{ }^{[14]}$

A preliminary check of arc melted monoboride alloys $\mathrm{Ta}_{1-\mathrm{x}}\{\mathrm{Ti}, \mathrm{Zr}, \mathrm{Hf}\}_{\mathrm{X}} \mathrm{B}(\mathrm{x} \sim 0.2)$ interestingly revealed in all 
three cases a major phase fraction of an FeB-type compound (i) either supporting a stabilization of the group-IV FeB-type phase, or (ii) a novel ternary phase separated from both

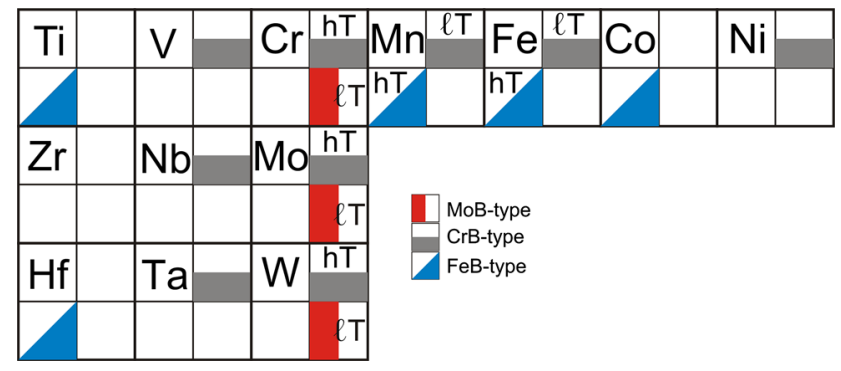

Fig. 2 Distribution of monoboride structure types among binary transition metal borides metal binaries. In any case the extended CrB-type phase solutions $\mathrm{Ta}_{1-\mathrm{x}}\{\mathrm{Zr}, \mathrm{Hf}\}_{\mathrm{x}} \mathrm{B}$ (up to $\mathrm{x} \sim 0.6$ ) claimed in the literature $^{[9,10]}$ (for details see Fig. 3) are not seen at subsolidus temperatures. Therefore this paper will address the formation of ternary FeB-type monoborides in the afore mentioned combinations at elevated temperatures.

\section{Experimental Details}

Alloys $\mathrm{Ta}_{1-\mathrm{x}} \mathrm{T}_{\mathrm{x}} \mathrm{B}(\mathrm{x}=0.32$ for $\mathrm{T}=\mathrm{Ti} ; \mathrm{x}=0.2,0.22$ for Hf and $\mathrm{x}=0.2,0.3$ for $\mathrm{Zr}$ ) were prepared from metal ingots of Ti,Zr,Hf (purity 99.9 mass \%), Ta-foil (99.9\%) and pieces of crystallized B (purity 99.5 mass\%), all from Alfa Johnson Matthey $\mathrm{GmbH}$, Germany, by repeated arc melting under argon. B-pieces - although wrapped in the corresponding



Fig. 3 Phase relations in isothermal sections as shown in the literature for the ternary diagrams $\mathrm{Ti}-\mathrm{Ta}-\mathrm{B}\left(1250{ }^{\circ} \mathrm{C}\right){ }^{[8]} \mathrm{Zr}-\mathrm{Ta}-\mathrm{B}$ $\left(1500{ }^{\circ} \mathrm{C}\right),{ }^{[9]}$ and Hf-Ta-B $\left(1400{ }^{\circ} \mathrm{C}\right) .{ }^{[10]}$ The small circles represent the composition of samples investigated in this work 
mass of Ta-foil - tend to shatter under the arc and were replenished in several meltings so that overall weight losses were kept below $1 \%$, however, the Ta:T ratio after synthesis was always within $0.1 \%$ of the nominal values (as monitored by EPMA - see below). With a melting temperature of $\mathrm{TaB}$ at $3090 \pm 15^{\circ} \mathrm{C},{ }^{[13,15]}$ subsolidus temperatures of the alloys near $\mathrm{TaB}$ are significantly higher than temperatures available for annealing in W-mesh furnaces. Therefore some reguli have been "heat-treated" directly after arc melting at subsolidus temperatures for $5 \mathrm{~min}$ running the arc at slightly lower energy than needed for melting. In the following, these alloys are labeled as "lowarc" samples.

Lattice parameters and standard deviations were determined by least squares refinements of room temperature $\mathrm{x}$ ray powder diffraction (XRD) data obtained from a GuinierHuber image plate employing monochromatic $\mathrm{Cu} \mathrm{K}_{1}$ radiation and Ge as internal standard $\left(a_{\mathrm{Ge}}=0.565791 \mathrm{~nm}\right)$. XRD-Rietveld refinements were performed with the FULLPROF program ${ }^{[16]}$ with the use of its internal tables for atom scattering factors.

All samples were polished using standard procedures. Microstructures/phase distributions were examined by scanning electron microscopy. For composition analyses, electron probe microanalysis (EPMA) measurements (point measurements and scans) were performed on a Zeiss Supra $55 \mathrm{VP}$ scanning electron microscope, operated at $20 \mathrm{kV}$ and $\sim 60 \mu \mathrm{A}$ employing energy dispersive $\mathrm{x}$-ray (EDX) analysis for determining the metal ratios Ta: $\{\mathrm{Ti}, \mathrm{Zr}, \mathrm{Hf}\}$. Pure elements served as standards.

Single crystals of $\mathrm{Ta}_{1-\mathrm{x}} \mathrm{Zr}_{\mathrm{x}} \mathrm{B}$ were isolated via mechanical fragmentation of an arc melted specimen with nominal composition $\mathrm{Ta}_{0.80} \mathrm{Zr}_{0.20} \mathrm{~B}$. X-ray single crystal diffraction (XSCD) data were collected at room temperature on a

Table 1 Lattice parameters (from XRD) and corresponding EPMA data for the phases in Ta $\mathbf{a}_{1-x} T_{x} B$ alloys, $\mathbf{T}=\mathbf{T i}, \mathbf{Z r}, \mathbf{H f}$

\begin{tabular}{|c|c|c|c|c|c|c|c|c|c|}
\hline \multirow[b]{2}{*}{ Composition/code } & \multirow[b]{2}{*}{$\mathbf{P C}^{\#}$} & \multirow[b]{2}{*}{ Phase(structure type) } & \multicolumn{3}{|c|}{ Lattice parameters, nm } & \multicolumn{3}{|c|}{ EPMA, at.\% $( \pm 0.5)$} & \multirow[b]{2}{*}{ Mass\% } \\
\hline & & & $\mathbf{a}$ & b & c & $\mathbf{T}$ & Ta & $\mathbf{B}^{\mathbf{S}}$ & \\
\hline $\mathrm{TaB}$ & Arc & $\mathrm{TaB}(\mathrm{CrB})$ & $0.32795(2)$ & $0.8671(2)$ & $0.31552(1)$ & $\ldots$ & 49.0 & 51.0 & 100 \\
\hline \multirow[t]{3}{*}{$\mathrm{Ta}_{0.8} \mathrm{Zr}_{0.2} \mathrm{~B}$} & Arc* & $(\mathrm{Ta}, \mathrm{Zr}) \mathrm{B}(\mathrm{FeB})$ & $0.6207(10)$ & $0.3174(2)$ & $0.4749(8)$ & 3.8 & 46.2 & 50 & 73 \\
\hline & & $(\mathrm{Ta}, \mathrm{Zr}) \mathrm{B}(\mathrm{FeB})$ & $0.6153(11)$ & $0.31648(5)$ & $0.4674(7)$ & 12.0 & 38.0 & 50 & 26 \\
\hline & & $\mathrm{Ta}(\mathrm{Zr})(\mathrm{W})$ & $\ldots$ & $\ldots$ & $\ldots$ & 92.5 & 7.5 & $\ldots$ & 1 \\
\hline \multirow[t]{3}{*}{$\mathrm{Ta}_{0.8} \mathrm{Zr}_{0.2} \mathrm{~B} \# 1$} & $\operatorname{Arc}(1)^{*}$ & $(\mathrm{Ta}, \mathrm{Zr}) \mathrm{B}(\mathrm{FeB})$ & $0.6134(25)$ & $0.31689(9)$ & $0.4839(73)$ & 3.2 & 46.8 & 50 & 35 \\
\hline & & $(\mathrm{Ta}, \mathrm{Zr}) \mathrm{B}(\mathrm{FeB})$ & $0.6162(3)$ & $0.31627(5)$ & $0.4704(1)$ & 7.1 & 42.9 & 50 & 63 \\
\hline & & $\mathrm{Ta}(\mathrm{Zr})(\mathrm{W})$ & $\ldots$ & $\ldots$ & $\ldots$ & 73.5 & 26.5 & $\ldots$ & 2 \\
\hline \multirow[t]{3}{*}{$\mathrm{Ta}_{0.8} \mathrm{Zr}_{0.2} \mathrm{~B} \# 2$} & $\operatorname{Arc}(2)^{*}$ & $(\mathrm{Ta}, \mathrm{Zr}) \mathrm{B}(\mathrm{FeB})$ & $0.6147(1)$ & $0.31638(5)$ & $0.46754(3)$ & 3.4 & 46.6 & 50 & 43 \\
\hline & & $(\mathrm{Ta}, \mathrm{Zr}) \mathrm{B}(\mathrm{CrB})$ & $0.32865(7)$ & $0.8687(11)$ & $0.31659(3)$ & 4.5 & 45.5 & 50 & 42 \\
\hline & & $\mathrm{Ta}(\mathrm{Zr})(\mathrm{W})$ & $\ldots$ & $\ldots$ & $\ldots$ & 18.7 & 81.3 & $\ldots$ & 15 \\
\hline \multirow[t]{3}{*}{$\mathrm{Ta}_{0.7} \mathrm{Zr}_{0.3} \mathrm{~B}$} & Arc & $(\mathrm{Ta}, \mathrm{Zr}) \mathrm{B}(\mathrm{FeB})$ & $0.6162(2)$ & $0.31616(1)$ & $0.4717(2)$ & 8.5 & 41.5 & 50 & 38 \\
\hline & & $(\mathrm{Ta}, \mathrm{Zr}) \mathrm{B}(\mathrm{FeB})$ & $0.6258(1)$ & $0.31647(1)$ & $0.46861(3)$ & 6.1 & 43.9 & 50 & 58 \\
\hline & & $\mathrm{Ta}(\mathrm{Zr})(\mathrm{W})$ & $\ldots$ & $\ldots$ & $\ldots$ & 89.9 & 10.1 & $\ldots$ & 4 \\
\hline \multirow[t]{2}{*}{$\mathrm{Ta}_{0.8} \mathrm{Hf}_{0.2} \mathrm{~B}$} & Arc & $(\mathrm{Ta}, \mathrm{Hf}) \mathrm{B}(\mathrm{FeB})$ & $0.6188(4)$ & $0.31576(1)$ & $0.4711(3)$ & 9.6 & 40.4 & 50 & 74 \\
\hline & & $(\mathrm{Ta}, \mathrm{Hf}) \mathrm{B}(\mathrm{FeB})$ & $0.6148(17)$ & $0.3170(1)$ & $0.4646(45)$ & 5.8 & 44.2 & 50 & 26 \\
\hline \multirow[t]{3}{*}{$\mathrm{Ta}_{0.78} \mathrm{Hf}_{0.22} \mathrm{~B}$} & Arc & $(\mathrm{Ta}, \mathrm{Hf}) \mathrm{B}(\mathrm{FeB})$ & $0.61800(7)$ & $0.31577(2)$ & $0.47025(4)$ & 8.6 & 41.4 & 50 & 58 \\
\hline & & $(\mathrm{Ta}, \mathrm{Hf}) \mathrm{B}(\mathrm{FeB})$ & $0.6168(2)$ & $0.31593(3)$ & $0.4693(2)$ & 7.2 & 42.8 & 50 & 23 \\
\hline & & $\mathrm{Ta}(\mathrm{Hf})(\mathrm{W})$ & $0.3376(1)$ & $\ldots$ & $\ldots$ & 41.3 & 58.7 & $\ldots$ & 19 \\
\hline \multirow[t]{6}{*}{$\mathrm{Ta}_{0.68} \mathrm{Ti}_{0.32} \mathrm{~B} \# 1$} & Slow cooled & $(\mathrm{Ta}, \mathrm{Ti})_{3} \mathrm{~B}_{4}$ (own) & $0.30961(3)$ & $0.32768(3)$ & $1.3921(5)$ & 11.4 & 28.8 & 59.9 & 23 \\
\hline & & $(\mathrm{Ta}, \mathrm{Ti}) \mathrm{B}(\mathrm{CrB})$ & $0.32645(1)$ & $0.86517(1)$ & $0.31387(1)$ & 9.3 & 40.7 & 50 & 4 \\
\hline & & $(\mathrm{Ta}, \mathrm{Ti}) \mathrm{B}(\mathrm{FeB})$ & $0.6121(4)$ & $0.31166(4)$ & $0.4646(1)$ & 12.8 & 37.2 & 50 & 46 \\
\hline & & $(\mathrm{Ta}, \mathrm{Ti}) \mathrm{B}(\mathrm{FeB})$ & $0.6158(2)$ & $0.31163(3)$ & $0.4685(1)$ & 11.0 & 39.0 & 50 & 13 \\
\hline & & $(\mathrm{Ta}, \mathrm{Ti}) \mathrm{B}_{2}\left(\mathrm{AlB}_{2}\right)$ & $0.30509(3)$ & $\ldots$ & $0.32412(5)$ & 13.4 & 19.7 & 66.9 & 13 \\
\hline & & $\mathrm{Ta}(\mathrm{Ti})(\mathrm{W})$ & $\ldots$ & $\ldots$ & $\ldots$ & $\ldots$ & $\ldots$ & $\ldots$ & $<1$ \\
\hline \multirow[t]{5}{*}{$\mathrm{Ta}_{0.68} \mathrm{Ti}_{0.32} \mathrm{~B} \# 2$} & Low arc & $(\mathrm{Ta}, \mathrm{Ti})_{3} \mathrm{~B}_{4}$ (own) & $0.3099(2)$ & $0.3277(2)$ & $1.396(5)$ & 10.3 & 34.6 & 55.1 & 9 \\
\hline & & (Ta,Ti)B (CrB) & $0.32761(3)$ & $0.8729(5)$ & $0.31253(2)$ & 9.3 & 40.7 & 50 & 7 \\
\hline & & $(\mathrm{Ta}, \mathrm{Ti}) \mathrm{B}(\mathrm{FeB})$ & $0.61222(8)$ & $0.31216(1)$ & $0.46469(4)$ & 12.8 & 37.2 & 50 & 72 \\
\hline & & $(\mathrm{Ta}, \mathrm{Ti}) \mathrm{B}_{2}\left(\mathrm{AlB}_{2}\right)$ & $\ldots$ & $\ldots$ & $\ldots$ & 15.4 & 17.0 & 67.7 & 5 \\
\hline & & $\mathrm{Ta}(\mathrm{Ti})(\mathrm{W})$ & $0.3288(8)$ & $\ldots$ & $\ldots$ & $\ldots$ & $\ldots$ & $\ldots$ & 7 \\
\hline
\end{tabular}


Bruker APEXII diffractometer equipped with a CCD area detector and an Incoatec Microfocus Source $\mathrm{I} \mu \mathrm{S}(30 \mathrm{~W}$, multilayer mirror, Mo $\mathrm{K}_{\alpha}$ ). Several sets of phi- and omegascans with $2.0^{\circ}$ scan width were measured at a crystaldetector distance of $3 \mathrm{~cm}$ (full sphere; $2^{\circ}<2 \theta<81^{\circ}$ ). The crystal structures were solved applying direct methods (program SHELXS-97) and refined against $\mathrm{F}^{2}$ (SHELXL$97-2)^{[17]}$ within the program WinGX. ${ }^{[18]}$ The crystal structures were all standardized with the program Structure Tidy. ${ }^{[19]}$ Further details concerning the experiments are given in Table 1.

\section{Results and Discussion}

\subsection{Formation of FeB-type Compounds in the Systems $T a-\{T i, Z r, H f\}-B$}

Table 1 summarizes the results of the combined evaluation of $\mathrm{x}$-ray lattice parameters and EPMA-compositions of the phases in the ternary alloys investigated. X-ray powder patterns in most cases document the existence of threephases: (i) a CrB-type phase (presumably linking to a solid solution extending from binary TaB, (ii) an FeB-type phase (which defines the ternary T-substituted phase) and (iii) in smaller amounts a softer matrix phase with W-type structure (consistent with the binary Ta-T solid solutions). EPMA line-scans over the large monoboride dendrites in the microstructures revealed significant coring effects in the solidification process, which is also obvious from the corresponding X-ray powder patterns: central and peripheral areas of the dendrites (or small dendrites) give rise to broadened x-ray intensity peaks. Furthermore primary dendrites and secondary precipitates in solidification produce identical $x$-ray intensity patterns (FeB-type) but with slightly different lattice parameters (doubling of peaks). Although derived from non-equilibrium alloys-some slowly cooled in the arc, some "quenched" (equivalent to cooling in the argon filled arc melter by removing the arc) from high temperature, the spread of lattice parameters and corresponding compositions of the FeB-type phase in each alloy can be taken as a sign for the extent of a phase region in the phase diagram.

For the binary Ta-B system, EPMA data as well as Rietveld refinement of an as cast alloy with composition of Ta50B50 (in at.\%) clearly document CrB-type as the only phase constituent. Whereas FeB-type solid solutions for $\mathrm{T}=\mathrm{Ti}, \mathrm{Zr}$,Hf comprise the compositions $\mathrm{Ta}_{1-\mathrm{x}} \mathrm{Ti}_{\mathrm{x}} \mathrm{B}$ for $0.22<\mathrm{x}<0.26$ and $\mathrm{Ta}_{1-\mathrm{x}} \mathrm{Zr}_{\mathrm{x}} \mathrm{B}$ for $0.06<\mathrm{x}<0.24$; the dendrites of $\mathrm{Ta}_{1-\mathrm{x}} \mathrm{Hf}_{\mathrm{x}} \mathrm{B}$ indicate a composition range for $0.12<\mathrm{x}<0.20$ (see Fig. 4). From the three transition elements zirconium is unique, as hitherto there has been no binary FeB-type compound ZrB experimentally observed. ${ }^{[13,20]}$ Therefore FeB-type $\mathrm{Ta}_{1-\mathrm{x}} \mathrm{Zr}_{\mathrm{x}} \mathrm{B}$ is a truly ternary phase, whilst the solutions $\mathrm{Ta}_{1-\mathrm{x}} \mathrm{T}_{\mathrm{x}} \mathrm{B}$ for $\mathrm{T}=\mathrm{Ti}, \mathrm{Hf}$ may be considered as a simple stabilization of binary FeBtype phases $\mathrm{TiB}\left(\mathrm{T}_{\mathrm{m}}=2190 \pm 25^{\circ} \mathrm{C}\right),{ }^{[12,13]}$ and $\mathrm{HfB}$ $\left(\mathrm{T}_{\mathrm{m}}=2100 \pm 20{ }^{\circ} \mathrm{C}\right)^{[12,13]}$ to higher temperatures via $\mathrm{Ta} /$ T-substitution. A similar situation is met for the homologous

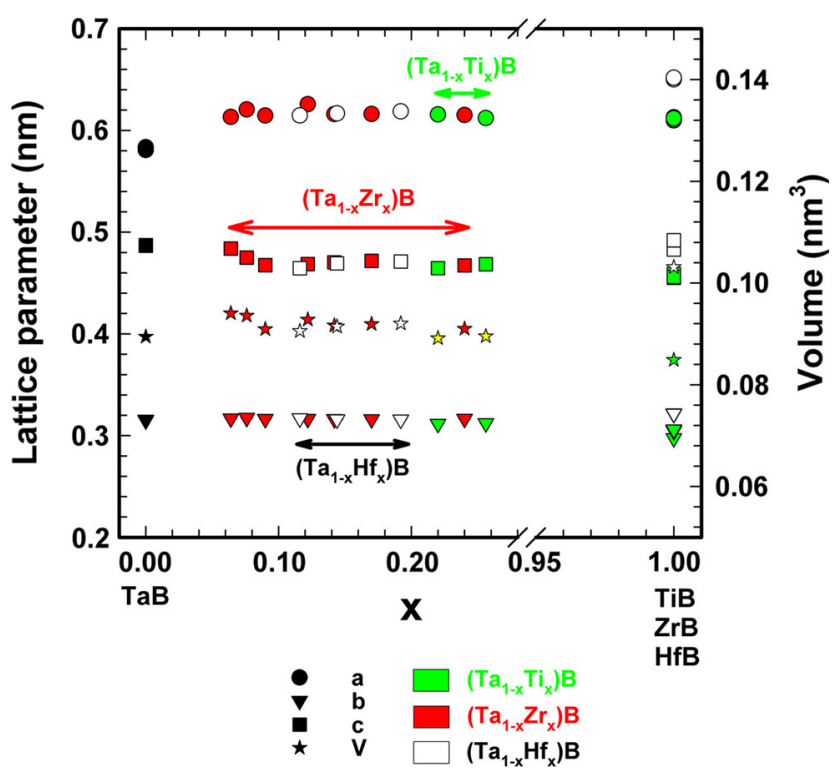

Fig. 4 Compositional dependence of lattice parameters and ranges of existence (indicated by arrows) of the FeB-type phases $\mathrm{Ta}_{1-\mathrm{x}}\{\mathrm{Ti}, \mathrm{Zr}, \mathrm{Hf}\}_{\mathrm{X}} \mathrm{B}$

section $\mathrm{Nb}_{1-\mathrm{x}} \mathrm{Ti}_{\mathrm{x}} \mathrm{B}$ for which large ternary mutual solid solubilities in the corresponding CrB- and FeB-type phases extend far into the ternary and which at $2650 \pm 15{ }^{\circ} \mathrm{C}$ are separated by a small two-phase region of about 5 at.\% metal. $^{[21]}$

3.1.1 The Ta-Ti-B System. Two samples in the Ta-Ti-B system with nominal composition $\mathrm{Ta}_{0.68} \mathrm{Ti}_{0.32} \mathrm{~B}$ were subjected to two different processing conditions: slow cooling by gradually reducing the power of the arc (\#1) and arc treatment at low power (\#2). Microstructure analyses of both samples (see Fig. 5a, b) show a significant segregation, where in one side the overall composition shifts towards the B-rich side, thus contains B-rich binary (Ta,Ti)-B phases such as $(\mathrm{Ta}, \mathrm{Ti})_{3} \mathrm{~B}_{4}$ and $(\mathrm{Ta}, \mathrm{Ti}) \mathrm{B}_{2}$. The other part of the samples shows only monoboride phase(s). This observation was also confirmed by analysis of XRD patterns via Rietveld refinements, which document B-rich binary (Ta,Ti)-B phases and monoborides with FeB/CrB-type.

Sample \#1 (see Fig. 5a) shows significant coring effects in the B-poor side, which is not visible in sample \#2 (Fig. 5b). Note that the different contrast in sample \#2 is due to grain orientation effects. The slowly cooled sample shows two FeB-type phases, (Ta,Ti)B, with very close Bragg positions. On the other hand the XRD pattern of sample \#2 does not reveal any doubling of FeB-type peaks, and the pattern could be satisfactorily refined with only one FeBtype phase (see Table 2). Despite XRD shows a small quantity of (Ta,Ti)B with CrB-type ( $~ 8 \mathrm{wt} . \%)$, it was not possible to distinguish the CrB-type from the FeB-type by phase composition, i.e. from the $\mathrm{Ta} / \mathrm{Ti}$ ratio as $\mathrm{EDX}$ measurement showed rather similar values. Nevertheless, we can differentiate three groups of data (only two in sample \#2), one with a highest $\mathrm{Ta} / \mathrm{Ti}$ ratio (4.4), and two sets with a lower $\mathrm{Ta} / \mathrm{Ti}$ ratio (3.5 and 2.9) (see Table 1 for details). In 


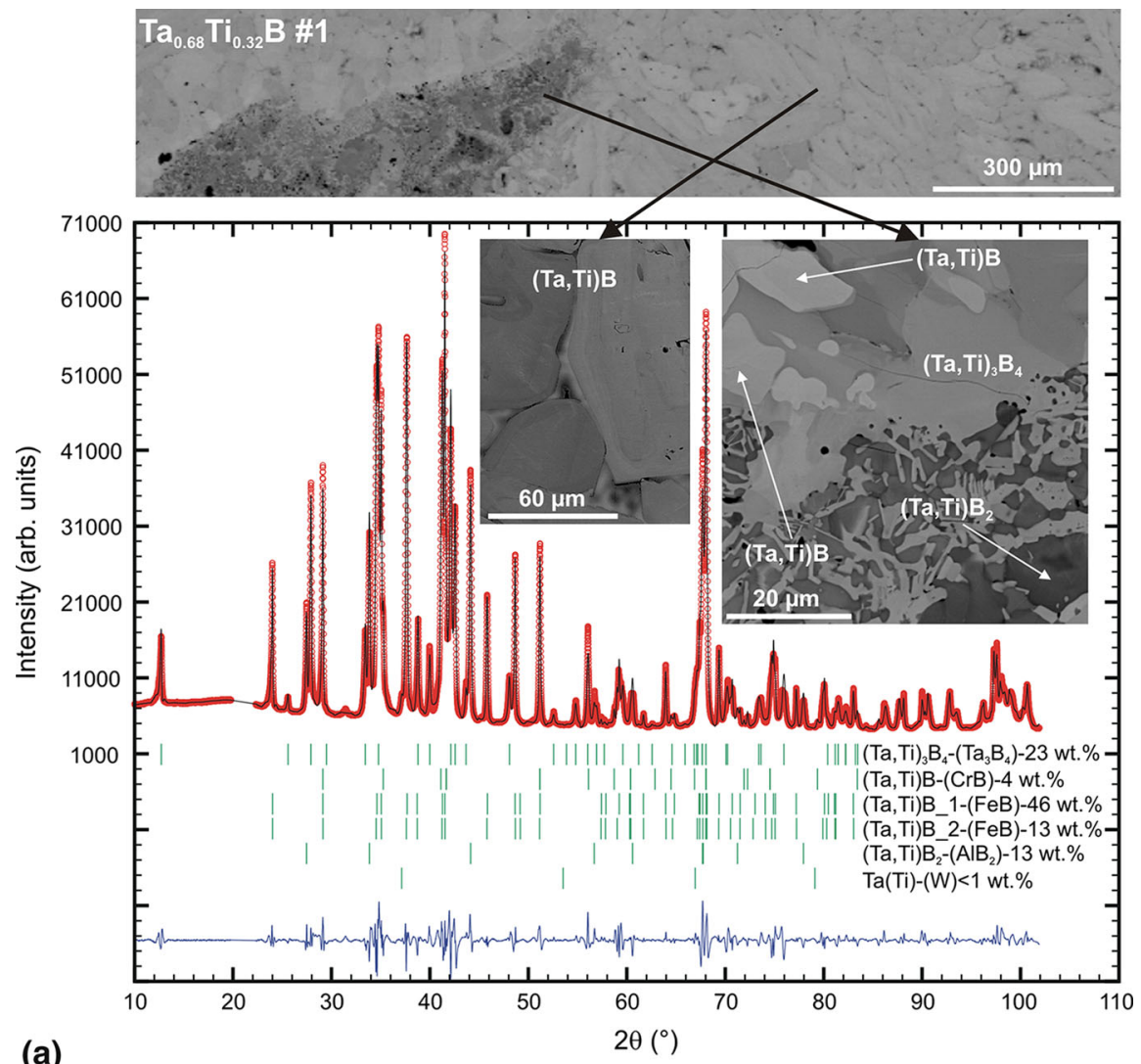

(a)
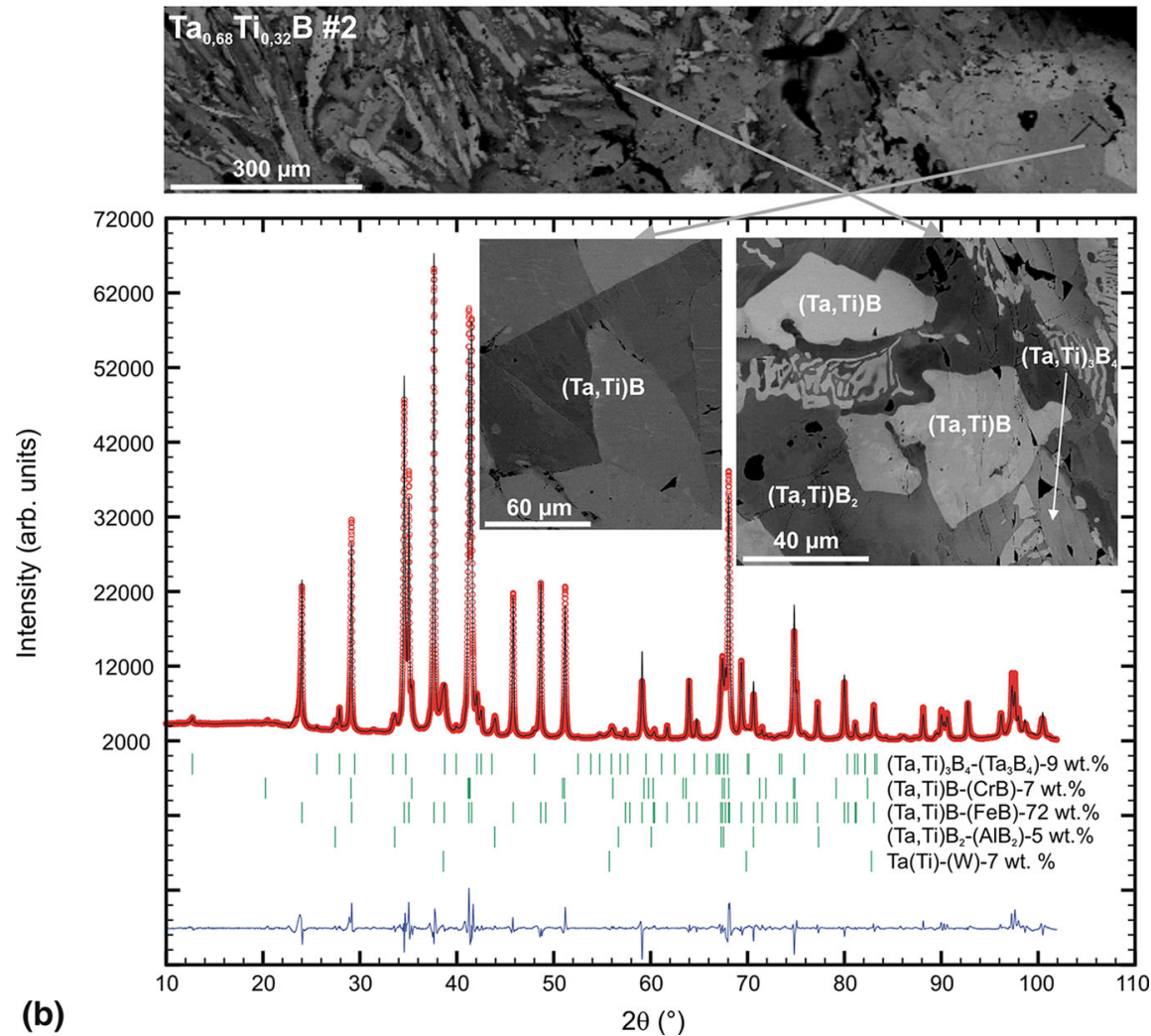

Fig. 5 (a) XRD pattern and micrographs of $\mathrm{Ta}_{0.68} \mathrm{Ti}_{0.32} \mathrm{~B} \# 1$ (slowly cooled) samples. (b) XRD pattern and micrographs of $\mathrm{Ta}_{0.68}$ $\mathrm{Ti}_{0.32} \mathrm{~B} \# 2$ (low arc power treated) sample 


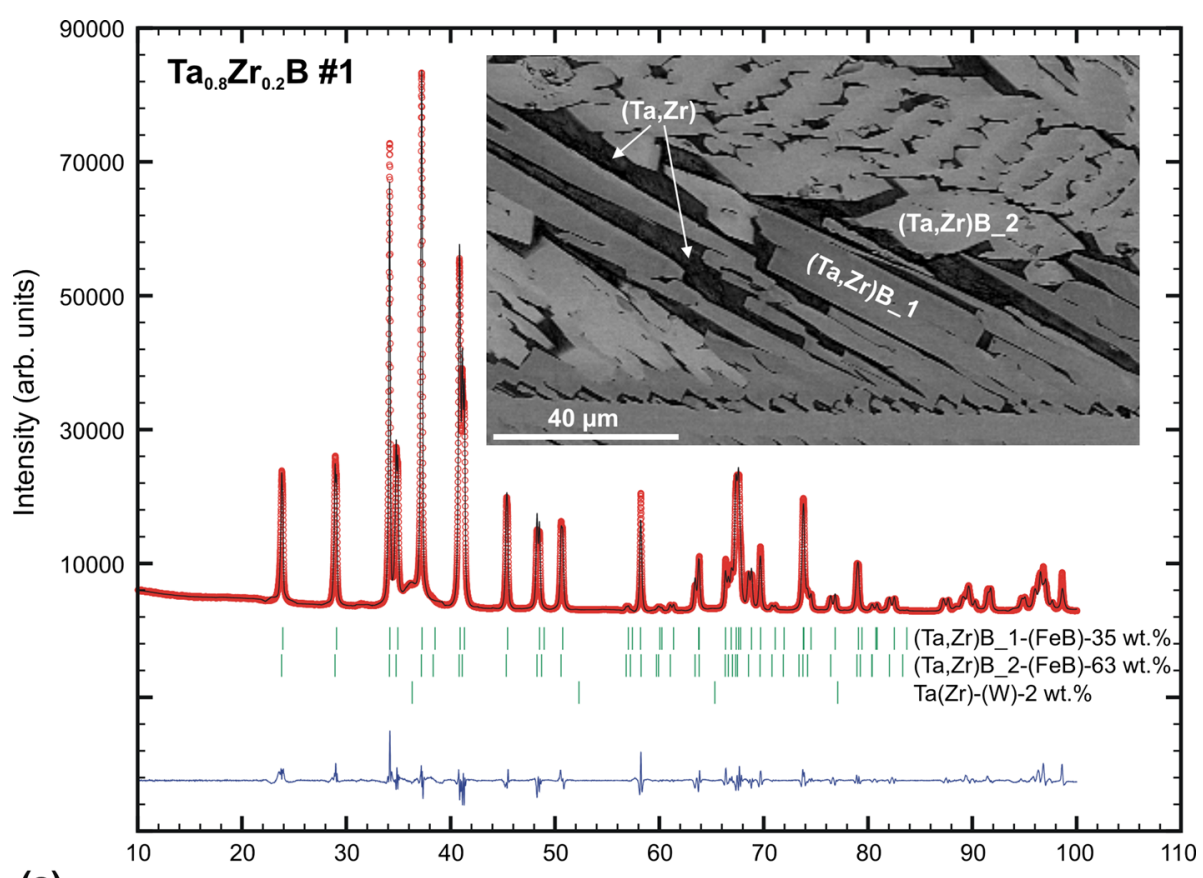

(a)

$2 \theta\left({ }^{\circ}\right)$

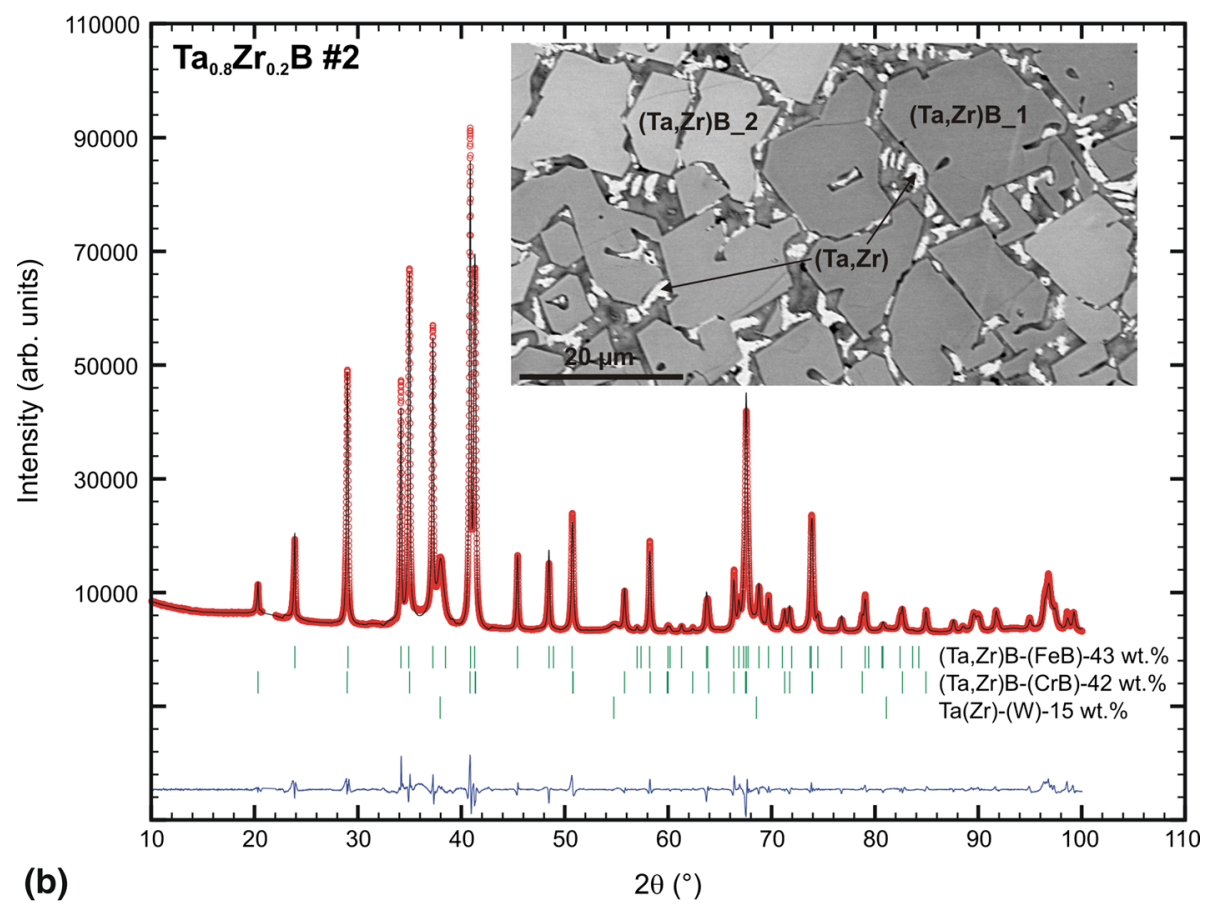

Fig. 6 (a) XRD pattern and micrographs of $\mathrm{Ta}_{0.80} \mathrm{Zr}_{0.20} \mathrm{~B} \# 1$ sample. (b) XRD pattern and micrographs of $\mathrm{Ta}_{0.80} \mathrm{Zr}_{0.20} \mathrm{~B} \# 2$ sample

such a case, however, we can assume that the monoboride with the highest $\mathrm{Ta} / \mathrm{Ti}$ ratio belongs to the CrB-type, which represent the end of solid solution (Ta,Ti)B with CrB-type, whereas those with lower $\mathrm{Ta} / \mathrm{Ti}$ ratio represents the end of the (Ta,Ti)B solid solution with FeB-type.

3.1.2 The Ta-Zr-B System. Formation of the FeB-type phase (Ta,Zr)B in the Ta-Zr-B system has been investigated with four samples: three with nominal composition
$\mathrm{Ta}_{0.80} \mathrm{Zr}_{0.20} \mathrm{~B}$ and one with $\mathrm{Ta}_{0.70} \mathrm{Zr}_{0.30} \mathrm{~B}$. In most cases samples look homogeneous except for $\mathrm{Ta}_{0.70} \mathrm{Zr}_{0.30} \mathrm{~B}$ where some parts contain a larger amount of $(\mathrm{Ta}, \mathrm{Zr})$ phase with $\mathrm{W}$ type. In all cases (Ta,Zr)B with FeB-type is the major constituent.

Figure $6 \mathrm{a}, \mathrm{b}$ shows the XRD patterns and micrographs of two $\mathrm{Ta}_{0.80} \mathrm{Zr}_{0.20} \mathrm{~B}$ samples with different phase constituents. Sample \#1 (Fig. 6a) shows only two FeB-type phases 
Table 2 Structural data for (Ta,Ti)B from Rietveld refinement (Guinier-Huber Image Plate, $\mathrm{Cu}_{\alpha} \mathbf{K}^{\circ} \leq \mathbf{2 \Theta} \leq \mathbf{1 0 0}^{\circ}$ ); standardized with program Structure Tidy ${ }^{[19]}$

\begin{tabular}{ll}
\hline Parameter/compound & $\mathbf{T a}_{\mathbf{1}-\mathbf{x}} \mathbf{T i}_{\mathbf{x}} \mathbf{B}, \mathbf{x}=\mathbf{0 . 2 5}$ \\
\hline Structure type & FeB \\
Space group type (No.) & Pnma (62) \\
$a(\mathrm{~nm})$ & $0.61222(8)$ \\
$b(\mathrm{~nm})$ & $0.31216(1)$ \\
$c(\mathrm{~nm})$ & $0.46469(4)$ \\
Reflections in refinement & 61 \\
Number of variables & 16 \\
$\mathrm{R}_{\mathrm{F}}=\left|\mathrm{F}_{\mathrm{o}}-\mathrm{F}_{\mathrm{c}}\right| / \mathrm{F}_{\mathrm{o}}$ & 0.0217 \\
$\mathrm{R}_{\mathrm{I}}=\mid \mathrm{I}_{\mathrm{o}}-\mathrm{I}_{\mathrm{c}} / / \mathrm{I}_{\mathrm{o}}$ & 0.0314 \\
$\mathrm{R}_{\mathrm{wP}}=\left[\mathrm{w}_{\mathrm{i}}\left|\mathrm{y}_{\mathrm{oi}}-\mathrm{y}_{\mathrm{ci}}\right|^{2} / \mathrm{w}_{\mathrm{i}}\left|\mathrm{y}_{\mathrm{oi}}\right|^{2}\right]^{1 / 2}$ & 0.113 \\
$\mathrm{R}_{\mathrm{P}}=\left|\mathrm{y}_{\mathrm{oi}}-\mathrm{y}_{\mathrm{ci}} / /\right| \mathrm{y}_{\mathrm{oi}} \mid$ & 0.10 \\
$\mathrm{R}_{\mathrm{e}}=\left[(\mathrm{N}-\mathrm{P}+\mathrm{C}) / \mathrm{w}_{\mathrm{i}} \mathrm{y}_{\mathrm{oi}}^{2}\right]^{1 / 2}$ & 0.0272 \\
$\chi^{2}=\left(\mathrm{R}_{\mathrm{wP}} / \mathrm{R}_{\mathrm{e}}\right)^{2}$ & 17.25 \\
$\mathbf{M}$ in $4 \mathrm{c}(\mathrm{x}, 1 / 4, \mathrm{z}) ;$ occ. & $\mathrm{x}=0.1758(1) ; \mathrm{z}=0.6239(1) ; 0.75(1) \mathrm{Ta}+0.25 \mathrm{Ti}$ \\
$\mathrm{B}_{\mathrm{iso}}\left(10^{2} \mathrm{~nm}^{2}\right)$ & 0.56 \\
$\mathbf{B}$ in $4 \mathrm{c}(\mathrm{x}, 1 / 4, \mathrm{z}) ;$ occ. & $\mathrm{x}=0.037(1) ; \mathrm{z}=0.111(2) ; 1.00(-)$ \\
$\mathrm{B}_{\text {iso }}\left(10^{2} \mathrm{~nm}\right)$ & 0.54 \\
\hline
\end{tabular}

(Ta,Zr)B in combination with smaller amounts of $(\mathrm{Ta}, \mathrm{Zr})$ matrix (W-type), with a high amount of $\mathrm{Zr}$ solved in the $(\mathrm{Ta}, \mathrm{Zr})$ matrix $(>70$ at.\% $\mathrm{Zr})$. This situation is also observed in the sample with higher amount of $\mathrm{Zr}$ $\left(\mathrm{Ta}_{0.7} \mathrm{Zr}_{0.3} \mathrm{~B}\right)$. On the other hand sample \#2 (Fig. $6 \mathrm{~b}$ ) shows almost equal amounts of FeB- and CrB-type phases $(\mathrm{Ta}, \mathrm{Zr}) \mathrm{B}$. In this sample the $(\mathrm{Ta}, \mathrm{Zr})$ matrix shows more $\mathrm{Ta}$ $(\sim 80$ at.\% Ta) than $\mathrm{Zr}$. The difference in the phase constitutions may arise from a somewhat lower B content in sample \#2. Note that in both samples the difference in the Ta: $\mathrm{Zr}$ ratio for the monoborides between different grains is not greater than 5 at.\%. Similar to the Ta-Ti-B system, one can assume that the monoboride with the higher Ta:Zr ratio corresponds to the CrB-type.

3.1.3 The Ta-Hf-B System. Two samples with nominal composition $\mathrm{Ta}_{0.80} \mathrm{Hf}_{0.20} \mathrm{~B}$ and $\mathrm{Ta}_{0.78} \mathrm{Hf}_{0.22} \mathrm{~B}$ reveal only (Ta,Hf)B monoborides with FeB-type. Both samples exhibit coring and secondary precipitation, which results in broadening and doubling of XRD reflections. The doubling can be identified easily in the $\mathrm{Ta}_{0.80} \mathrm{Hf}_{0.20} \mathrm{~B}$ sample (Fig. 7a), whilst for $\mathrm{Ta}_{0.78} \mathrm{Hf}_{0.22} \mathrm{~B}$ the reflections between the two FeB-type phases (Ta,Hf)B closely overlap (see Fig. 7b). This phenomenon is also confirmed by EPMA measurements, which show significant differences in the Ta:Hf ratio measured throughout the sample $\mathrm{Ta}_{0.80} \mathrm{Hf}_{0.20} \mathrm{~B}(\sim 5$ at.\%) whilst the difference for alloy $\mathrm{Ta}_{0.78} \mathrm{Hf}_{0.22} \mathrm{~B}$ is less than 2 at.\%. These differences are seen in EPMA line scans across large grains with coring effect, whereas small grains reveal compositions corresponding to the outer rims of the cored large grains.

\subsection{The Crystal Structure of $T a_{0.76} Z r_{0.24} B$ with FeB-type}

In order to prove the FeB-type structure, a single crystal (SC) was chosen from the system Ta-Zr-B. The crystal was broken from an arc melted specimen with nominal composition $\mathrm{Ta}_{0.8} \mathrm{Zr}_{0.2} \mathrm{~B}$, for which EPMA revealed a composition
$\mathrm{Ta}_{38} \mathrm{Zr}_{12} \mathrm{~B}_{50}$ (in at. $\% \equiv \mathrm{Ta}_{0.76} \mathrm{Zr}_{0.24} \mathrm{~B}$ ) for rather homogeneous crystallites of $\sim 25 \mu \mathrm{m}$ diameter, suitable for $\mathrm{x}$-ray structure analysis. An FeB-type compound in this system will thus constitute a truly ternary phase, as a stable monoboride phase was hitherto experimentally not recorded in the high purity binary Zr-B phase diagram. The "ZrB"-phase with $\mathrm{NaCl}$-type, which is occasionally listed in structure and phase diagram compilations, was shown to be a $(\mathrm{C}, \mathrm{N}, \mathrm{O})$ stabilized phase (for a detailed discussion see Ref 14.).

Analyses of the $\mathrm{x}$-ray single crystal intensity data, particularly of the systematic extinctions (observed for $0 \mathrm{kl}$, $k+l=2 \mathrm{n}+1$ and $h k 0$ for $h=2 \mathrm{n}+1$ ), prompted an orthorhombic unit cell $(\mathrm{a}=0.617526(11) \mathrm{nm}$, $\mathrm{b}=0.316427(5), \quad \mathrm{c}=0.469934(9) \mathrm{nm})$ consistent with space group symmetry Pnma (No. 62), which, as the highest symmetric one, was chosen for further structure analysis. Direct methods delivered a structure solution with metal atoms in site $4 \mathrm{c}$. The boron atoms were unambiguously located via a difference Fourier synthesis in a further $4 \mathrm{c}$-site. A free variable on the $\mathrm{Ta} / \mathrm{Zr}$ ratio yields only a slightly lower $\mathrm{Zr}$ content than that determined by EPMA. With only one $4 \mathrm{c}$-site for the metal atoms, no ordering among $\mathrm{Ta} / \mathrm{Zr}$ atoms is possible and no evidence exists from the $\mathrm{x}$-ray diffraction spectra for supercell reflections. A final refinement (with $\mathrm{Ta} / \mathrm{Zr}$ ratio inserted from EPMA) inferring anisotropic atom displacement parameters (ADP's) in general but isotropic ADP's for the boron site converged to an $\mathrm{R}$-value $\mathrm{R}_{\mathrm{F} 2}=0.0165$ with Fourier ripples in the electron density of less than $3.2 \mathrm{e}^{-} / \AA^{3}$ at $0.09 \mathrm{~nm}$ from $\mathrm{B}$. The value of the isotropic ADP of boron atoms confirms full occupancy of the B-site corresponding to a B-defect free monoboride. The parameters derived from refinement for $\mathrm{Ta}_{0.76} \mathrm{Zr}_{0.24} \mathrm{~B}$ are listed in Table 3 including interatomic distances. A search for the structure type in Pearson's Crystal Data ${ }^{[1]}$ and in ICSD (Fachinformationszentrum Karlsruhe), ${ }^{[2]}$ involving also the Wyckoff sequence $c^{2}$, 

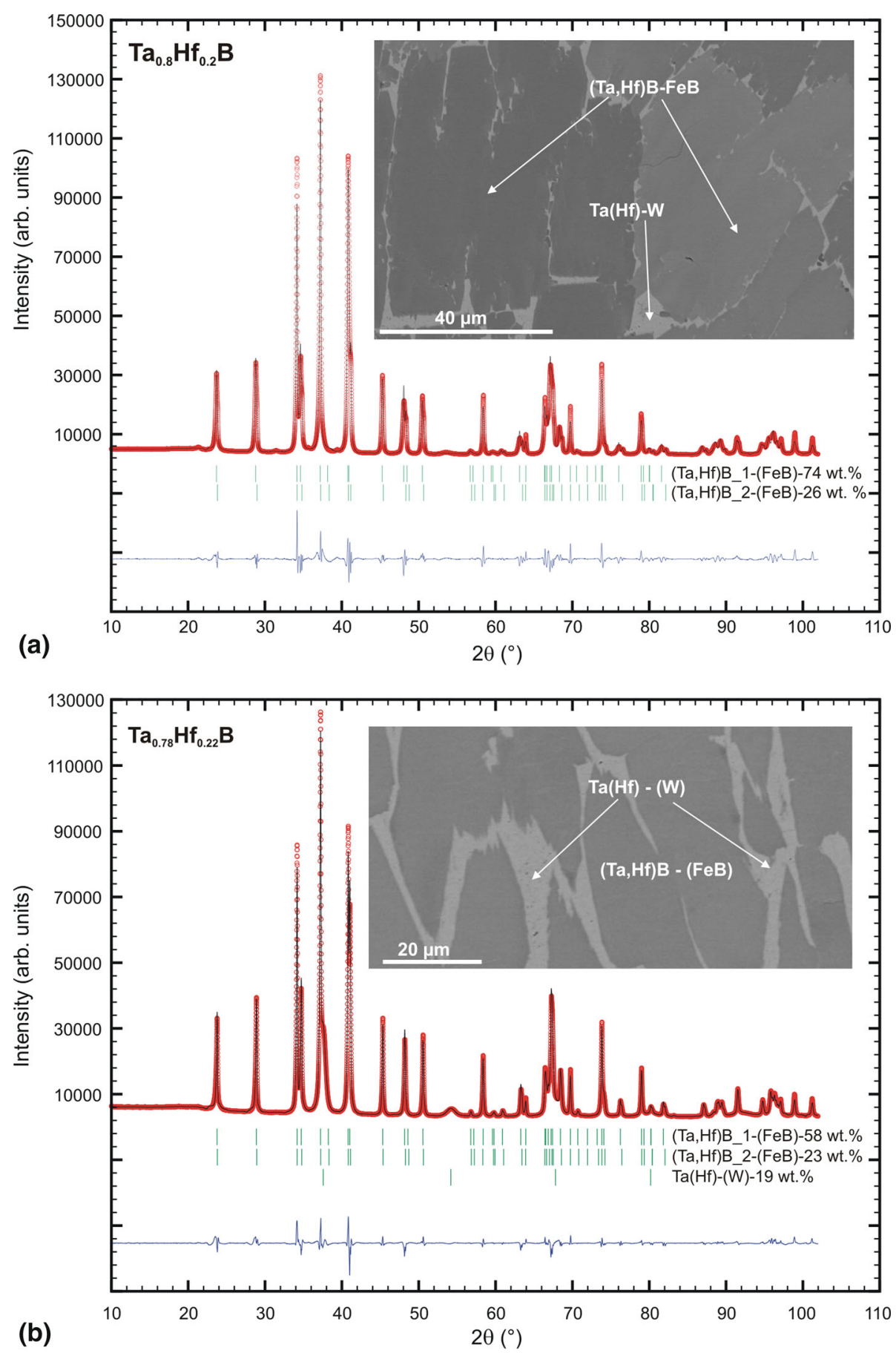

Fig. 7 (a) XRD pattern and micrographs of $\mathrm{Ta}_{0.80} \mathrm{Hf}_{0.20} \mathrm{~B}$ sample. (b) XRD pattern and micrographs of $\mathrm{Ta}_{0.78} \mathrm{Hf}_{0.22} \mathrm{~B}$ sample

prompted isotypism with the (undisturbed) structure of FeB in its high temperature form.

Interatomic distances in Table 3 show that boron-boron distances, $\mathrm{d}_{\mathrm{B}-\mathrm{B}}=0.188 \mathrm{~nm}$, in $\mathrm{Ta}_{0.78} \mathrm{Zr}_{0.22} \mathrm{~B}$ appear somewhat increased with respect to the boron chain in binary FeB with significantly smaller metal (Fe) atoms: $d_{B}$ $\mathrm{B}=0.1785 \mathrm{~nm} \quad$ (from $\mathrm{x}$-ray $\mathrm{SC}$ data; ${ }^{[23]}$ or $\mathrm{d}_{\mathrm{B}-}$ $\mathrm{B}=0.1783 \mathrm{~nm}$, from unpolarized neutron diffraction $\mathrm{SC}$ data $\left.^{[24]}\right)$. Bonds from $\mathrm{B}$ to the six $\mathrm{Ta} / \mathrm{Zr}$ atoms within the trigonal prisms are rather homogeneous, $0.240 \mathrm{~nm}<\mathrm{d}_{\mathrm{B}-\mathrm{Ta}}$ / $\mathrm{Zr}<0.243 \mathrm{~nm}$, and are close to the sum of radii $\left(\mathrm{R}_{\mathrm{Ta}}=0.1467 \mathrm{~nm}, \mathrm{R}_{\mathrm{Zr}}=0.1602, \mathrm{R}_{\mathrm{B}}=0.088 \mathrm{~nm}^{[25]}\right)$ documenting a strong metal-boron interaction. The characteristic feature of compounds with the FeB-type structure (see Fig. 1,8 ) is the infinite boron zig-zag chain (along the $b$ axis) with a bond distance range of $0.165 \mathrm{~nm}<\mathrm{d}_{\mathrm{B}}$ ${ }_{\mathrm{B}}<0.190 \mathrm{~nm}$, and with bond angles of $\phi_{\mathrm{B}-\mathrm{B}-\mathrm{B}} \sim 115^{\circ}$. $^{[2]}$ As each boron atom is close to the centre of a triangular 
Table 3 X-ray single crystal data ${ }^{\#}$ for $\mathrm{Ta}_{0.76} \mathrm{Zr}_{0.24} \mathrm{~B}$ (FeB-type; space group Pnma) at $\mathrm{RT}$ (anisotropic displacement parameters $U_{i j}$ in $\left[10^{-2} \mathrm{~nm}^{2}\right]$ )

\begin{tabular}{|c|c|}
\hline Parameter/compound & $\mathrm{Ta}_{0.76} \mathrm{Zr}_{0.24} \mathrm{~B}$ \\
\hline Phase composition (EPMA, at.\%)* & $\mathrm{Ta}_{38} \mathrm{Zr}_{12} \mathrm{~B}_{50}$ \\
\hline Composition from refinement (at.\%) & $\mathrm{Ta}_{38} \mathrm{Zr}_{12} \mathrm{~B}_{50}$ \\
\hline$a[\mathrm{~nm}]$ & $0.617256(11)$ \\
\hline$b[\mathrm{~nm}]$ & $0.316427(5)$ \\
\hline$c[\mathrm{~nm}]$ & $0.469934(9)$ \\
\hline$\theta$ range $(\mathrm{deg})$ & $2.7<2 \theta<80.74$ \\
\hline Mosaicity & 0.54 \\
\hline Number of variables & 10 \\
\hline Reflections in refinement & $282 \geq 4 \mathrm{r}\left(\mathrm{F}_{\mathrm{o}}\right)$ of 319 \\
\hline $\mathrm{R}_{\mathrm{F} 2}=\left|\mathrm{F}_{\mathrm{o}}^{2}-\mathrm{F}_{\mathrm{c}}^{2}\right| / \mathrm{F}_{\mathrm{o}}^{2}$ & 0.0165 \\
\hline wR2 & 0.0451 \\
\hline $\mathrm{R}_{\text {Int }}$ & 0.053 \\
\hline GOF & 1.203 \\
\hline Extinction (Zachariasen) & $0.007(1)$ \\
\hline Residual density $\mathrm{e}^{-} / \AA^{3} ; \max$; min & $3.21 ;-3.14$ \\
\hline \multicolumn{2}{|l|}{ Atom positions } \\
\hline $0.76(4) \mathrm{Ta}+0.24 \mathrm{Zr}$ in $4 \mathrm{c}(\mathrm{x}, 1 / 4, \mathrm{z})$ & $\mathrm{x}=0.17579(3) ; \mathrm{z}=0.62342(5)$ \\
\hline $\mathrm{U}_{11} ; \mathrm{U}_{22} ; \mathrm{U}_{33} ; \mathrm{U}_{23}=\mathrm{U}_{12}=0 ; \mathrm{U}_{13}$ & $0.0021(1) ; 0.0026(1) ; 0.0019(1) ; 0.0002(1)$ \\
\hline $\mathrm{B}$ in $4 \mathrm{c}(\mathrm{x}, 1 / 4, \mathrm{z})$; occ. & $\mathrm{x}=0.0315(9) ; \mathrm{z}=0.1004(13) ; 1.00(-)$ \\
\hline $\mathrm{U}_{\text {iso }}$ & $0.0055(9)$ \\
\hline
\end{tabular}

Interatomic distances, $\mathrm{nm}$; Standard deviation $<0.0001$

\begin{tabular}{|c|c|c|}
\hline Atom 1 & Atom 2 & Distance, $\mathbf{n m}$ \\
\hline \multirow[t]{6}{*}{$\mathrm{B}$} & $2 \mathrm{~B}$ & 0.1883 \\
\hline & $2 \mathrm{Ta} / \mathrm{Zr}$ & 0.2404 \\
\hline & $2 \mathrm{Ta} / \mathrm{Zr}$ & 0.2412 \\
\hline & $\mathrm{Ta} / \mathrm{Zr}$ & 0.2413 \\
\hline & $\mathrm{Ta} / \mathrm{Zr}$ & 0.2434 \\
\hline & $\mathrm{Ta} / \mathrm{Zr}$ & 0.2614 \\
\hline \multirow[t]{9}{*}{$\mathrm{Ta} / \mathrm{Zr}$} & $2 \mathrm{~B}$ & 0.2404 \\
\hline & $2 \mathrm{~B}$ & 0.2412 \\
\hline & B & 0.2413 \\
\hline & $\mathrm{B}$ & 0.2434 \\
\hline & $\mathrm{B}$ & 0.2614 \\
\hline & $2 \mathrm{Ta} / \mathrm{Zr}$ & 0.2925 \\
\hline & $4 \mathrm{Ta} / \mathrm{Zr}$ & 0.2977 \\
\hline & $2 \mathrm{Ta} / \mathrm{Zr}$ & 0.3164 \\
\hline & $2 \mathrm{Ta} / \mathrm{Zr}$ & 0.3307 \\
\hline \multicolumn{3}{|c|}{${ }^{*}$ Standardized with program Structure Tidy ${ }^{[19]}$} \\
\hline \multicolumn{3}{|c|}{ * The highest $\mathrm{Zr} / \mathrm{Ta}$ ratio (after EPMA) for the sample from where the single crystal was selected } \\
\hline \multicolumn{3}{|c|}{ Bonding angle in boron zig-zag chain: $\phi_{\mathrm{B}-\mathrm{B}-\mathrm{B}}=114.3^{\circ}$} \\
\hline
\end{tabular}

metal prism, infinite columns of those prisms connected along their rectangular faces follow the direction of the boron chains. One of the rectangular faces of the triangular metal prism is capped by a metal atom linking adjacent columns of prisms. With $\mathrm{d}_{\mathrm{B}-\mathrm{Ta} / \mathrm{Zr}}=0.2614 \mathrm{~nm}$ the distance to the capping metal atom is only slightly longer than those to the prism-forming $\mathrm{Ta} / \mathrm{Zr}$ atoms. Due to strong covalent boron-boron bonds, boron defects in the metal borides with CrB-type, MoB-type and FeB-type are rare (see Ref 2).

\section{Conclusions}

The existence of novel high temperature FeB-type phases $\mathrm{Ta}\{\mathrm{Ti}, \mathrm{Zr}, \mathrm{Hf}\} \mathrm{B}$ have been confirmed either from as cast or arc treated samples by $\mathrm{x}$-ray powder and single crystal diffraction and electron probe microanalysis. In most cases the FeB-type monoboride is the major constituent, which suggests that this phase is the high temperature stabilization 


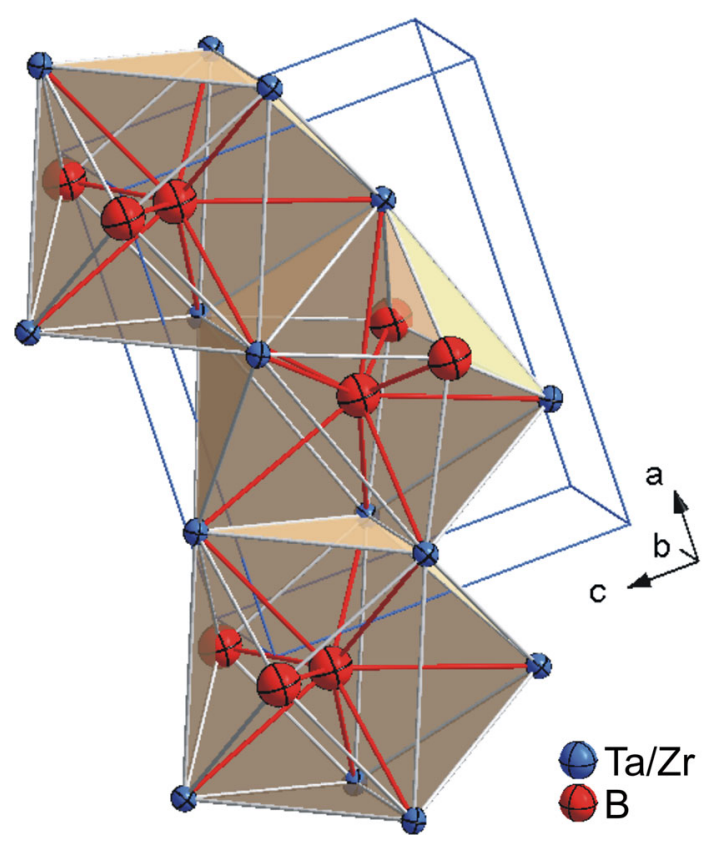

Fig. 8 Connectivity of mono-capped triangular prisms of $\mathrm{Ta} / \mathrm{Zr}$ atoms in $\mathrm{Ta}_{0.8} \mathrm{Zr}_{0.2} \mathrm{~B}$ sharing triangular faces. Each mono-capped metal prism is centered by a boron atom: $\left[\mathrm{Ta}(\mathrm{Zr})_{7}\right] \mathrm{B}$ forming infinite -B-B-B- chains running parallel to the $b$-axis inferring also infinite chains of Ta/Zr-prisms sharing their rectangular faces. Ta/ $\mathrm{Zr}$-atoms in blue are presented with ADPs from single crystal refinement, isotropic B-atoms (ADP from SC refinement) are red (Color figure online)

of a binary group IV metal monoboride. This holds true for $\mathrm{Ti}$ and $\mathrm{Hf}$, while for $\mathrm{Zr}$ the evaluation proves that $(\mathrm{Ta}, \mathrm{Zr}) \mathrm{B}$ with FeB-type is a true ternary phase, as no stable FeB-type monoboride has been documented in the binary $\mathrm{Zr}-\mathrm{B}$ system. An x-ray single crystal study of $\mathrm{Ta}_{0.78} \mathrm{Zr}_{0.22} \mathrm{~B}$ unambiguously proved isotypism of the crystal structure with the FeB-type. EPMA evaluations show that the novel FeB-type phases $\mathrm{Ta}_{1-\mathrm{x}}\{\mathrm{Ti}, \mathrm{Zr}, \mathrm{Hf}\}_{\mathrm{x}} \mathrm{B}$ form via substitution of $\mathrm{Ta}$ in TaB by small amounts of group IV elements ( $\sim 3$ at.\% of $\mathrm{Zr}, \sim 7$ at.\% $\mathrm{Hf}$, and $\sim 10$ at.\% Ti).

\section{Acknowledgments}

The research reported herein was supported by the Austrian Federal Ministry of Science and Research (BMWF) under the scholarship scheme: Technology Grant Southeast Asia (Ph.D) in the frame of the ASEA UNINET. The authors furthermore acknowledge FAPESP (São Paulo, Brazil), Grant 97/06348-4, for financial support. Part of this research was supported by the European Commission under the 6th Framework program through the Key Action: Strengthening the European Research Area, Research Infrastructures; Contract n.: RII3-CT-2003-505925.

\section{References}

1. P. Villars and K. Cenzual, Pearson's Crystal Data-Crystal Structure Database for Inorganic Compounds, Release 2014/ 15, ASM International, Materials Park, 2014

2. P. Rogl, Formation of Borides, Inorganic Reactions and Methods: Formation of Bonds to Group-I, -II, and -IIIB Elements, Vol 13, J.J. Zuckerman and A.P. Hagen, Ed., Wiley, New York, 1991, p 84-85

3. D. Hohnke and E. Parthé, AB, Compounds with Sc, Y and Rare Earth Metals. II. FeB and CrB Structures of Monosilicides and Germanides, Acta Crystallogr., 1966, 20(4), p $572-582$

4. H. Boller, W. Rieger, and H. Nowotny, Systematische Stapelfehler in der $\delta$-WB-Phase bei Bor-Unterschuß. Monatshefte für Chem. Verwandte Teile anderer Wiss. 1964, 95 (6), p 1497-1501. in German

5. I. Smid and P. Rogl, Phase Equilibria and Structural Chemistry in Ternary Systems: Transition Metal-Boron-Nitrogen, Science of Hard Materials, Inst. Phys. Conf. Ser., Vol 75, E.A. Almond, C.A. Brookes, and R. Warren, Ed., Adam Hilger Ltd, Bristol, 1986, p 249-257

6. T. Kanaizuka, Invar like Properties of Transition Metal Monoborides $\mathrm{Mn}_{1-\mathrm{x}} \mathrm{Cr}_{\mathrm{x}} \mathrm{B}$ and $\mathrm{Mn}_{1-\mathrm{x}} \mathrm{Fe}_{\mathrm{x}} \mathrm{B}$, Mater. Res. Bull., 1981, 16(12), p 1601-1608

7. W.B. Pearson, The Crystal Chemistry and Physics of Metals and Alloys, Wiley, New York, 1972, p 520-523

8. A.S. Sobolev, Y.B. Kuz'ma, T.E. Soboleva, and T.F. Fedorov, Phase Equilibria in Tantalum-Titanium-Boron and TantalumMolybdenum-Boron Systems, Sov. Powder Metall. Met. Ceram., 1968, 7(1), p 48-51

9. Y.V. Voroshilov and Y.B. Kuz'ma, Reaction of Zirconium with the Transition Metals and Boron. Sov, Powder Metall. Met. Ceram., 1969, 8(11), p 941-944

10. Y.B. Kuz'ma, S.I. Svarichevskaya, and V.S. Telegus, Systems Titanium-Tungsten-Boron, Hafnium-Tantalum-Boron, and Tantalum-Tungsten-Boron, Sov. Powder Metall. Met. Ceram., 1971, 10(6), p 478-481

11. P. Rogl and P.E. Potter, A Critical Review and Thermodynamic Calculation of the Binary System: Hafnium-Boron, Calphad, 1988, 12(3), p 207-218

12. H. Bittermann and P. Rogl, Critical Assessment and Thermodynamic Calculation of the Ternary System Boron-HafniumTitanium (B-Hf-Ti), J. Phase Equilibria, 1997, 18(1), p 24-47

13. E. Rudy. Ternary Phase Equilibria in Transition Metal-BoronCarbon-Silicon Systems, Part V; Compendium of Phase Diagram Data, Technical Report AFML-TR-65-2, Part V; Air Force Materials Laboratory Wright Patterson Air Force Base: Ohio, USA, 1969; p 1-698

14. P. Rogl and P.E. Potter, A Critical Review and Thermodynamic Calculation of the Binary System: Zirconium-Boron, Calphad, 1988, 12(2), p 191-204 
15. V.M. Chad, F.F. Ferreira, B. Paulino, C.G. Coelho, and C.A. Nunes. Thermodynamic Modelling of the Ta-B System. In Congresso Anual da ABM 63rd; 2008; p 1412-1423, in Portuguese

16. J. Rodríguez-Carvajal, Recent Developments of the Program FULLPROF, Comm. Powder Diffr. IUCr Newsl., 2001, 26, p 12-19

17. G.M. Sheldrick, A Short History of SHELX, Acta Crystallogr. A, 2007, 64(1), p 112-122

18. L.J. Farrugia, WinGX Suite for Small-Molecule Single-Crystal Crystallography, J. Appl. Crystallogr., 1999, 32(4), p 837-838

19. L.M. Gelato and E. Parthé, STRUCTURE TIDY-A Computer Program to Standardize Crystal Structure Data, J. Appl. Crystallogr., 1987, 20(2), p 139-143

20. H. Duschanek, Rogl, P, Phase Diagrams of Ternary MetalBoron-Carbon Systems, G. Effenberg, Ed., ASM International, Materials Park, 1998, p 445-485
21. D.B. Borisov, L.V. Artyukh, A.A. Bondar, P.S. Martsenyuk, A.V. Samelyuk, N.I. Tsiganenko, O.S. Fomichov, and T.Y. Velikanova, Titanium-Boride Eutectic Materials. Structure of the Ti-Nb-B Alloys and Phase Equilibria, Powder Metall. Met. Ceram., 2007, 46(1-2), p 58-71

22. Inorganic Crystal Structure Database 2014/1; Fachinformationszentrum: Karlsruhe, Germany, 2014

23. C. Kapfenberger, B. Albert, R. Pöttgen, and H. Huppertz, Structure Refinements of Iron Borides $\mathrm{Fe}_{2} \mathrm{~B}$ and $\mathrm{FeB}, Z$. für Krist., 2006, 221(5-7/2006), p 477-481

24. R.S. Perkins and P.J. Brown, Charge and Spin Density in the Iron Borides, J. Phys. F, 1974, 4(6), p 906-920

25. E. Teatum, K. Gschneidner, and J. Waber, LA-2345; US Department of Commerce: Washington, DC, 1960; reproduced in W.B. Pearson, The Crystal Chemistry and Physics of Metals and Alloys, Wiley, New York, 1972, p. 151 